\title{
Nutrtional Assessment of Hetero-clarias and Oreochromis niloticus under Two Drying Preservation Methods
}

\author{
Fapohunda Olawumi*, Adebayo Israel, Esan Ibiyemi \\ Department of Fisheries and Aquaculture Management, Faculty of Agricultural Sciences, Ekiti State University, Nigeria
}

Received November 11, 2019; Revised March 4, 2020; Accepted May 13, 2020

Copyright@2020 by authors, all rights reserved. Authors agree that this article remains permanently open access under the terms of the Creative Commons Attribution License 4.0 International License

\begin{abstract}
This study was conducted to compare the effect of Sun drying and Oven drying on the nutritional composition of two fish species (Heteroclarias and Oreochromis niloticus). Ten freshly harvested catfish (Heteroclarias) and Tilapia (Oreochromis niloticus) were shared into two parts; a part was sun - dried for 12 days (7 hours daily) between the hours of 9 a.m -4 p.m at an average temperature range of $23-35.9^{\circ} \mathrm{C}$, temperature range in Iworoko Ekiti between February - March (According to Norwegian Met Institute) and the other part was dried using laboratory electric oven at a temperature range of $80^{\circ} \mathrm{C}$ for 5 days (4 hours daily). Each part was in three (3) replicates. The proximate compositions of the dried samples (Mean moisture, protein, lipid, ash, fibre, carbohydrate) were determined. The changes in moisture, protein and carbohydrate contents including energy value were found to be significant $(\mathrm{P}<0.05)$ for the two processing (drying) methods. Ash and lipid contents showed no significant differences $(P>0.05)$ for the two drying methods used in this study. The changes in the fibre contents was found to be significant $(\mathrm{P}<0.05)$ in the Heteroclarias species for both processing methods while it was not significant $(\mathrm{P}>0.05)$ in the Oreochromis niloticus species for both processing methods. This result indicates that drying methods have effects on the proximate compositions of fish species (Heteroclarias and Oreochromis niloticus). The overall assessment showed that; for taste; the highest mean value recorded was $6.0 \pm$ 0.0 and $5.3 \pm 0.6$ in Oven dried Heteroclarias and Oven dried Oreochromis niloticus respectively. The least mean value $3.0 \pm 0.5$ was recorded in the sun dried Oreochromis niloticus followed by $3.4 \pm 0.6$ in sun dried Heteroclarias. The result further indicated that there is significant difference between organoleptic qualities of oven dried and sun dried samples of the same fish species.
\end{abstract}

Keywords Sun Drying, Oven Drying, Nutritional
Composition, Heteroclarias, Oreochromis niloticus

\section{Introduction}

Today food security is a major concern in Nigeria because of the increasing gap between population and rate of food production. Fish production remains a vital tool to promote food and nutritional security in Nigeria. Fish is a major source of protein and its harvesting, handling, processing and distribution provide livelihood for millions of people as well as is source of foreign exchange for many countries (Al-Jufaili and Opara, 2006). Fish is one of the most important sources of animal protein available in the tropics and has been widely accepted as a good source of protein and other elements for the maintenance of health of human beings (Andrew, 2001). Fish constitutes about $69.6 \%$ of the total supply of protein available to Nigeria. Consumption of fish provides an important nutrient to a large number of people worldwide and thus makes a very significant contribution to nutrition.

Fish is an extremely perishable food item (Agbo et al., 2002). Soon after death, fish begins to spoil. In the healthy live fish, all the complex biochemical reactions are balanced and the fish flesh is sterile. After death however, irreversible change that results in fish spoilage begins to occur. The resultant effect is the decomposition of the fish (Akinola et al., 2006). Various factors are responsible for fish spoilage. The quality of fish at capture is important in determining the rate of spoilage. Notably are the fish health status, the presence of parasites, bruises and wounds on the skin and the mode by which the fish was captured. The caught fish quality depends on the handling and preservation of the fish as received from the hands of the fishers after capture. The handling and the preservation 
practice after capture affects the degree of spoilage of the fish (Akinneye et al., 2007).

The methods that are commonly employed are the traditional techniques such as salting/brining, sun-drying and smoking which also increase fish availability to the consumers (Abolagba et al., 1996). The salting prior to drying, involves the removal of moisture and the introduction of salt until the attainment of the right texture, flavor and colour. Preservation is through moisture removal and the presence of salt which at the right level inhibits chemical, microbial and enzymatic activities and also attack harmful biological agents (Abraham and Oramadike, 2011).

Akinola et al. (2006) reported that despite the rudimentary nature of process of traditional methods, lack of control over the drying rate, sometimes results in under-drying or over-drying. During this process exposure of fish to unexpected winds, dust, dirt, insect infestation, and contaminants such as flies are some other problems encountered. These methods are still predominant in Nigeria. To reduce post-harvest losses and to improve the quality of fish and fishery products, traditional processing technology must be improved upon in Nigeria. This includes upgrading the traditional fish processing technology and adoption of solar dryer. Artificial dryers such as solar dryer, kiln, oven, etc, have long been in existence, some of them are powered electrically, by sun, gas or natural fuel such as firewood, charcoal, wood and saw dust (Bolaji, 2005).

The drying of fish in an oven consists of a period of several hours in which the fish is cooked and dried with low burning fire for a certain period with the production of moderate amount of smoke. The length of this latter period varies with the required keeping quality. The moisture of the dried products varies between an estimated $40 \%$ in the higher ranges and $10-20 \%$ in lower ranges. The quality of the product is judged on degree of drying, appearance, damages and insect infestation which influences the fish price.

There is a need to adopt an adequate preservation method for fish, so that at the cost of preserving fish, the nutritional composition of the fish is not altered unconsciously. This study is aimed at comparing the nutritional composition of Hetero-clarias and Oreochromis niloticus after processing with different processing techniques (oven - drying and sun - drying).

The main focus of this study was to investigate the effects of drying (oven-drying and sun-drying) on the nutritional composition of Hetero-clarias and Oreochromis niloticus. The proximate composition of dried fishes was determined when preserved by two different drying methods. The knowledge obtained from this study will improve the capacity of local fishing and aqua - cultural communities on appropriate handling and processing of fish therefore reducing the rate of spoilage, wastage and nutritional loss during processing. This study is essential because about $75 \%$ of artisanal catch and $20 \%$ of industrial catch is dried/smoked and distributed traditionally and that there is inadequate information relating to losses due to traditional and modern processing of fish.

\section{Materials and Methods}

\subsection{Experimental Fishes}

Ten freshly harvested catfish (Hetero-clarias) and Tilapia (Oreochromis niloticus) were obtained from Durante fish farms, Ibadan, Oyo - State. The average weight of catfish (Hetero-clarias) was $400 \mathrm{~g}$ while that of Tilapia (Oreochromis niloticus) was 300g. The twenty fishes of both species were shared into two equal portions; ten was used for oven drying and the other ten for sun drying.

\subsection{Methods of Processing}

The major processing methods employed were; gutting, washing, cutting, brining, hanging and drying (Oven drying and Sun drying).

Drying: The fish samples were dried using two different methods (sun-drying and oven-drying) and fish samples for each treatment were in triplicates.

Sun-drying: A portion of the fish samples was sun-dried for 12days (7 hours/day) in broad day sunlight. The fish samples were placed in a rectangular clean plastic tray that was covered with a mosquito net to prevent access by flies and other insects. Samples were sun dried from $9.00 \mathrm{am}$ to $4.00 \mathrm{pm}$ daily. The temperature ranges in Iworoko Ekiti in which the samples were sundried was within the range of $23-35.9^{\circ} \mathrm{C}$, according to the Norwegian Met Institute. The tray was always kept indoors after $4.00 \mathrm{pm}$ for 12 days after which they were taken to the laboratory for proximate analysis.

Oven-drying: The other portion of the fish samples was dried using laboratory electric oven (DHG - 9101. ISA). The well drained fish samples were oven dried at a temperature of $80^{\circ} \mathrm{C}$ for 5 days (4 hours daily) after which the proximate analysis was carried out.

\subsection{Proximate Analysis of the Fish Samples}

The nutritional analysis was carried out in the Biochemistry Laboratory of Ekiti State University (EKSU), Ado Ekiti. The proximate compositions were assayed as described by AOAC, 2005. The fish samples were analyzed for crude protein, lipids, carbohydrate, moisture and ash contents, after the drying process. Each analysis was carried out in triplicate. The fish samples were crushed and blended using a domestic blender (Model MGB 1212). 


\subsection{Determination of Protein Content}

The Microkjelahl method was used in the determination of the crude protein content.

The percentage Nitrogen in the sample was determined using the following formula.

$$
100=\left[\begin{array}{llll}
\left(\begin{array}{lll}
A & x & B
\end{array}\right) & 0.14
\end{array}\right]
$$

$\mathrm{C}$

Percentage crude protein $=$ Nitrogen in sample $\times 6.25$ where;

A $=$ Hydrochloric acid used in titration (ml)

$\mathrm{B}=$ Normality of standard acid

$\mathrm{C}=$ Weight of sample (g)

\subsection{Determination of Ash Content}

$1.0 \mathrm{~g}$ of dry matter was weighed into a crucible, incinerated in a muffle furnace at temperature of $500^{\circ} \mathrm{C}$ for a period of between 24 and 48 hours. After complete ashing, samples were cooled in a desiccator and weighed afterward to give the Total Organic Matter (TOM) otherwise called the ash using the expression below:

$\%$ Ash $=($ Weight of crucible + TOM $)-($ Weight of crucible $)$ $\mathrm{x} 100$

\subsection{Determination of Lipid Content}

Lipid extraction was carried out using Soxhlet extraction method.

The percentage of extracted lipid was calculated as:

$$
\% \text { Lipid }=\frac{\mathrm{W} 4-\mathrm{W} 3}{\mathrm{~W} 2-\mathrm{W} 1} \times 100
$$

\subsection{Determination of Moisture Content}

The hot oven method was adopted.

The percentage moisture was calculated as follows:

$$
\% \text { Moisture }=\underline{\mathrm{W} 2}-\mathrm{W} 3 \times 100
$$

W1

\subsection{Determination of Crude Fibre}

$3.00 \mathrm{~g}$ of the defatted sample was added to $200 \mathrm{ml} \mathrm{H}_{2} \mathrm{SO}_{4}$ in a boiling solution and was boiled gently for 30 minutes, stirring occasionally. Titration was done in a vacuum flask. The filter paper was washed with boiling water and the residue was transferred into a flask. $200 \mathrm{ml} \mathrm{NaOH}$ boiling solution was allowed to boil for 30 minutes in a filter vacuum and the residue was washed with boiling water, $\mathrm{HCl}$ solution and again with boiling water. Fat was removed by washing with petroleum ether. The dry crucible was set at $105^{\circ} \mathrm{C}$ and allowed to cool in a dryer. The crucible was left with the residue in the furnace at $550^{\circ} \mathrm{C}$ for 3 hours. It was removed after this period and allowed to cool in a desiccator.

$$
\text { The percentage crude fiber }=\underline{A-B}
$$

\section{$\mathrm{C}$}

Where:

A=Weight of crucible with dry residue (g)

$\mathrm{B}=$ Weight of crucible with Ash (g)

$\mathrm{C}=$ Weight of Sample (g)

\subsection{Carbohydrate Determination}

Only traces of carbohydrates are contained in fish muscles, in the form of sugars, phosphates and glycogen. Other tissues like liver contain larger amount as glycogen. Carbohydrate was estimated by difference.

The percentage carbohydrate $=(100-\mathrm{P}-\mathrm{M}-\mathrm{F}-\mathrm{A})$

Where;

$\mathrm{P}=$ Percentage protein

$\mathrm{M}=$ Percentage moisture

$\mathrm{F}=$ Percentage fat

$\mathrm{A}=$ Percentage ash

\subsection{Organoleptic Analysis}

Organoleptic qualities of the dried fish samples were evaluated by setting up a 4 - member panel familiar with the qualities of dried fish. The panelist rated the samples for parameters like flavor, texture, appearance, and palatability based on a 5 - point hedonic scale after being trained on how to apportion mark to each parameter. Dried fish samples were issued out in conjunction with questionnaires. The fish samples were given out with questionnaires for the panel members to feel and taste the fish products and score was based on how it appealed to the taste, texture, palatability and flavor to the panel. The questionnaires were returned and marks were appropriately apportioned to each parameter Panelists are to use the modified 5- point hedonic scale described by Eyo (2001) which is as follows:

\subsection{Modified Scores Remark}

$$
\begin{aligned}
& \text { 1-1.9 Unacceptable } \\
& \text { 2-2.9 Fair } \\
& \text { 3-3.9 Medium } \\
& \text { 4-4.9 Good } \\
& \text { 5-6.0 Very good }
\end{aligned}
$$

\subsection{Statistical Analysis}

The Independent Samples $\mathrm{T}$ - Test was employed to compare the differences between the means of the two 
treatment groups (Sun - drying and Oven - drying).

\section{Results and Discussion}

The moisture contents in oven-dried fish products from different fish species: Hetero-clarias and Oreochromis niloticus were $8.60 \pm 0.2$ and $8.4 \pm 0.6$ respectively while the sun dried samples had $14.88 \pm 0.7$ and $12.64 \pm 2.0$ respectively. In this study, more water contents were rapidly removed in the fish exposed to oven-drying than sun-drying. This observation is in agreement with Omafuvbe and Kolawole, (2004), who reported that oven-drying generally, achieved the required moisture content in food earlier and more uniformly than sun-drying. According to Silver et al, (2008), the water content in fish affects the microbiological and chemical stability, physical properties, processing, storage and distribution of fish. A safe moisture level of 6 to $8 \%$ in dried fish has been recommended in order to prevent spoilage due to microbe and pest proliferation (Effiong and Mohammed, 2008).

The results in this study show that the ash content in the oven dried Hetero-clarias $(15.57 \pm 0.6)$ was higher than that of sun dried Heteroclarias (15.08 \pm 1.0 ), and also the ash content in oven dried Oreochromis niloticus (17.34 \pm 1.5) was higher than the sun dried Oreochromis niloticus (17.04 \pm 0.1$)$. Owaga et al., (2009) reported that total ash value is an indicator of the total mineral element contents in fish; this shows that oven dried fish samples had more mineral content than sun dried samples.

The fiber contents were low in all the treatments. The highest was recorded in the sun dried Oreochromis niloticus (1.6 \pm 0.6 ). Akinnneye et al, (2010), did not detect any fiber in the three species (Heterotis niloticus, Sardinella spp, Bonga spp) that were subjected to oven and sun drying. Although, a diet high in soluble fiber can reduce total serum cholesterol by as much as $15 \%$ in man, Fusco, (2011) reported that there is a meager or no fiber in animal products such as meat, fish, eggs or dairy products.

In this study, the highest fat content was recorded in oven dried Hetero-clarias (28.26 \pm 1.9$)$ compared to sun dried Hetero-clarias. Oven dried Oreochromis niloticus, sun dried Oreochromis niloticus and which are $26.77 \pm 2.1$, $20.05 \pm 1.0$ and $19.70 \pm 0.5$ respectively. Studies revealed that lipid contents fluctuate considerably with age, feed and sexual cycle of fish, Jorkan et al, (2008). Based on the 5\% fat composition criteria for discriminating lean fish from fatty species, Ackman, (1989), it was apparent that Hetero-clarias and Oreochromis niloticus could be regarded as fatty fish species. According to Puwustien et al, (1999), the fats exuded with moisture evaporation and the extended heat treatment during drying could increase the fat contents in fish. Augustsson, (2003) reported that fish with moderate fat contain low cholesterol and are good sources of Omega - 3 fatty acids which protect against heart rhythm disorders and has benefits for blood clotting and blood vessel function.

The crude protein level in the sun dried Hetero-clarias and Oreochromis niloticus fish samples were $35.12 \pm 1.7$ and $33.33 \pm 1.0$ respectively. The oven dried fish samples have the higher crude protein content; $43.02 \pm 2.6$ and $40.73 \pm 1.1$ for Hetero-clarias and Oreochromis niloticus respectively. The highest crude protein content was recorded in the oven dried Heteroclarias $(43.02 \pm 2.6)$. The high level of protein of the oven dried fish samples insinuates that protein Nitrogen was not lost during dehydration at a temperature of $80^{\circ} \mathrm{C}$; this is in accordance to the findings of Gokoglu et al, (2004), Tao and Linchun, (2008). The authors are of the view that the high level of protein in the oven dried products may be due to of dehydration of fish which concentrated the proteins during the heat treatment, thus enhancing the nutritional value of the oven dried fish.

The highest carbohydrate content was remarkable in sun dried Oreochromis niloticus with $15.34 \pm 0.6$ compared to others; $12.48 \pm 0.5,4.02 \pm 1.0$ and $7.95 \pm 1.1$ for oven dried Oreochromis niloticus, oven dried Heteroclarias, and sun dried Heteroclarias respectively. The main function of carbohydrate is to supply energy to the body and to perform various physiological functions. Low carbohydrate diets have been reported to lower blood pressure by causing weight loss and improving the insulin sensitivity in diabetics (Arora and McFarlane, 2005).

Table 1. Proximate Composition of Oven-dried and Sun- dried Hetero-clarias

\begin{tabular}{|c|c|c|c|c|c|c|c|}
\hline Fish species & Moisture \% & Ash \% & Fat \% & Fibre \% & Protein \% & CHO \% & Energy value (Kj/g) \\
\hline Ovendried & $8.60 \pm 0.2$ & $15.57 \pm 0.6$ & $28.26 \pm 1.9$ & $0.57 \pm 0.1$ & $43.02 \pm 2.6$ & $4.02 \pm 1.0$ & $1,845.36 \pm 37.8$ \\
\hline Sundried & $14.88 \pm 0.7$ & $15.08 \pm 1.02$ & $77.21 \pm 1.0$ & $0.20 \pm 0.1$ & $35.12 \pm 1.7$ & $7.95 \pm 1.1$ & $1,722.68 \pm 79.3$ \\
\hline
\end{tabular}

Table 2. Proximate Composition of Oven dried and Sun dried Oreochromis niloticus

\begin{tabular}{|c|c|c|c|c|c|c|c|}
\hline Fish species & Moisture \% & Ash \% & Fat \% & Fibre \% & Protein \% & CHO \% & Energy value (Kj/g) \\
\hline Ovendried & $8.4 \pm 0.6$ & $17.34 \pm 1.5$ & $20.05 \pm 1.0$ & $1.0 \pm 0.1$ & $40.73 \pm 1.1$ & $12.48 \pm 0.5$ & $1,646.42 \pm 31.7$ \\
\hline Sundried & $12.64 \pm 2.0$ & $17.04 \pm 0.1$ & $70.0 .5 \pm 1.0$ & $1.6 \pm 0.6$ & $33.33 \pm 1.0$ & $.34 \pm 0.6$ & $1,556.29 \pm 19.2$ \\
\hline
\end{tabular}




\section{The Organoleptic Properties}

The organoleptic properties of Oven dried and Sun dried fish species are shown in Tables 3 and 4. The overall assessment shows that; for taste; the highest mean value recorded was $6.0 \pm 0.0$ and $5.3 \pm 0.6$ in Oven dried Hetero-clarias and Oven dried Oreochromis niloticus respectively. The least mean value $3.0 \pm 0.5$ was recorded in the sun dried Oreochromis niloticus followed by $3.4 \pm$ 0.6 in sun dried Heter-oclarias. For the texture; the highest mean value recorded was $5.3 \pm 0.6$ in oven dried Hetero-clarias which is followed by $3.8 \pm 0.1$ in oven dried Oreochromis niloticus and sun dried Hetero-clarias. The least mean value $2.5 \pm 0.5$ was found in sun dried Oreochromis niloticus.

Table 3. Organoleptic Properties of the Oven - dried and Sun - dried Heteroclarias

\begin{tabular}{|c|c|c|c|c|}
\hline Fish species & Taste & Texture & Palatability & Flavour \\
\hline Oven-dried & $6.0 \pm 0.0$ & $5.3 \pm 0.6$ & $5.7 \pm 0.4$ & $5.6 \pm 0.6$ \\
\hline Sundried & $3.4 \pm 0.6$ & $3.7 \pm 0.8$ & $2.9 \pm 0.7$ & $3.1 \pm 0.5$ \\
\hline
\end{tabular}

Table 4. Organoleptic Properties of Oven - dried and Sun - dried Oreochromis niloticus

\begin{tabular}{|c|c|c|c|c|}
\hline Fish species & Taste & Texture & Palatability & Flavour \\
\hline Oven-dried & $5.3 \pm 0.6$ & $3.8 \pm 0.1$ & $4.5 \pm 0.0$ & $4.5 \pm 0.1$ \\
\hline Sundried & $3.0 \pm 0.6$ & $2.5 \pm 0.5$ & $2.1 \pm 0$. & $3.1 \pm 0.6$ \\
\hline
\end{tabular}

The oven dried fish species has the highest value of palatability $5.7 \pm 0.4$ and $4.5 \pm 0.0$ in Heteroclarias and Oreochromis niloticus respectively. The lowest mean value $2.1 \pm 0.5$ was recorded in sun dried Oreochromis niloticus. For flavor; the oven dried fish species (Heteroclarias and Oreochromis niloticus) has the highest mean value of $5.6 \pm 0.6$ and $4.5 \pm 0.1$ respectively. The least mean value was recorded in sun dried Oreochromis niloticus and sun dried Hetero-clarias. This result further indicates that there is a significant difference between the organoleptic qualities of Oven dried and Sun dried fish species.

\section{Conclusions}

It can therefore be concluded that, the quality of the oven dried products is better than that of the sun dried products; this might be as a result of the elevated and uniform temperature in the oven, which brought about a quick removal of moisture than the sun dried products. The quick removal of moisture helps in retarding spoilage activities and insect infestation as well as microbial contamination on the products and this brings a better output than the sun dried products. The most remarkable organoleptic characteristics is the taste. The taste of the oven dried Hetero-clarias sample is the most pleasant while the sun dried Oreochromis niloticus had the least pleasant taste.

\section{Recommendations}

In order to reduce post-harvest losses and increase nutritional security, the method of fish preservation in Nigeria need to be improved upon as a strategy to promote agricultural resilience. It is recommended that protein deficient patients can build up their muscles from the consumption of oven dried fish species (such as Heteroclarias and Oreochromis niloticus). Also, improved technologies should be developed and made available for oven drying fish products in order to reduce post-harvest spoilage. Finally, the government should help small scale fish processors by constructing large community ovens/kilns which they could rent and use for processing, thus creating a source of revenue for the government through fish processing. This study thereby supports the application of electric oven drying as an efficient drying method for fish processing nationwide.

\section{REFERENCES}

[1] Abolagba, O. J., V. A. Okonji and D. A. Enobakhare, 1996. Salting of fish as means of reducing damage by Dermestes maculates (Coleoptera). Nig. J. Entomol., 13: 81 - 86.

[2] Abraham - Olukayode, A. O. and Oramadike, C. E. 2011. Biochemical and Bacteriological Assessment of Fresh and Processed Croaker fish (Pseudolithus elongated). J. Sci. Technol. Res., 10: 100 - 105.

[3] Afolabi, O. A., Arawomo, O. A. and Oke, O. L. 1984. Quantity changes of Nigerian traditional processed freshwater species 1: Nutritive and organoleptic changes. $J$. Food Technol., 19: 333-340.

[4] Ackman, R. G., 1989. Nutritional Composition of fats in sea foods. Prog. Food Nutr. Sci., 13: 161 - 289.

[5] Agbo, A, O., Ezeri, G. N. O., Ikenwiewe, B. N., Alegbieye, N. O., Akomolade, D. T. (2002). A comparative study of different storage methods on the shelf life of smoked current fish. J. Aquat. Sci., 17(2): 134-136.

[6] Akinneye, J. O., Amoo, I. A., Arannilewa, S. T. (2007). Methods on the nutritional composition of three species of (Bonga sp., Sardinella sp., and Heterotis niloticus). J. Fish. Int., 2(1): 99-103.

[7] Akinola, O. A., Akinyemi, A. A. and Bolaji, B. O. (2006). Evaluation of traditional and solar drying system towards enhancing fish story and presentation in Nigeria (Abeokuta local government as a case study). J. Fish. Int., 1(2-4): 44-49.

[8] Al-Jufaili, M. S, and Opara, L. U. (2006). Status of fisheries harvest industry in the sultanate of Oman: Part 1 handling and marketing system of fresh fish. J. Fish. Int. 1(24): 144-149b.

[9] Andrew, A. E. (2001). Fish - Processing Technology, University of Ilorin Press, Nigeria, pp.7 - 8.

[10] AOAC., 2005. Official Methods of Analysis (18th ed.). 
Association of Official Analytical Chemists International, Maryland, USA.

[11] Augustsson, K., Michaud, D. and Rimm, E. 2003. A prospective study of intake of fish and marine fatty acids and prostate cancer. Cancer Epidemiol. Biomarkers Prev., 12 (1): 64.

[12] Bala, B. K. and M. R. A. Mondol, 2001. Experimental Investigation on Solar Drying of Fish Using Solar Tunnel Dryer. Drying Technol., 19: 427- 436.

[13] Bolaji, B. O., 2005. Performance evaluation of a simple solar dryer for food preservation. Book of Proceedings of 6th Annual Engineering Technology, Federal University of Technology, Minna, Nigeria.

[14] Castrillion, A., M. Navarro and E. A. L. Varez-Pontes, 1987.Changes in chemical composition and nutritional quality of fried Sardine (Clupea pilchardus) produced by frozen storage and micro wave reheating. J. Sci. Food Agric., 75: 123-132.

[15] Effiong, B. and Mohammed, I. 2008. Effect of Seasonal Variation on the Nutrient Composition in Selected Fish Species in Lake Kainji-Nigeria. Natural Science, 6(2).

[16] Eves, A. and R. Brown, 1993. The Effect of Traditional Drying Processes on the Nutritional Values of Fish. Tropical Sci., 33: 183-189.

[17] Eyo, A. A., 2001. Fish Processing Technology in the Tropics. National Institute for Freshwater Fisheries Research (NIFFR), New Bussa, Nigeria, pp: 10-170.

[18] Gokoglu, N. P., Yorlikaya, P. and Cengis, E. 2004. Effect of Cooking Methods on the Proximate Composition and Mineral Contents of Rainbow trout (Onchorhyndus mykiss). Food Chemistry, 84: 19-22.

[19] Omafuvbe, B. and Kolawole, D. 2004. Quality assurance of stored pepper (Piper guineense) using controlled processing methods. Pakistan Journal of Nutrition, 3(4): 224-249.

[20] Owaga, E., Onyango, C. and Njoroge, C. 2009. Assessment of insect contamination, acid insoluble ash content and color characteristics of traditionally sun-dried and oven-dried dagaa (Rastrineobola argentea). Journal of Applied Biosciences, 24:1497-1507.

[21] Puwustien, P., Judprasong, K., Kettwan, E., Vasanachitt, K., Nakngamanong, Y. and Bhattachrjee, L. 1999. Proximate composition of raw and cooked Thai freshwater and Marinefish J. Food Composition and Analysis, 12:9-16.

[22] Silver, V., 2008. Determination of moisture content and water activity in algae and fish by thermo - analytical techniques. Quím. Nova, 31, 4. Nutritional and Odorous Properties of Grass Carp (Ctenopharyngodon idellus) Fillets. Food Chem., 110 (3): 647-653. 